\title{
Thai Sign Language Image Recognition for the Hearing-Impaired using Radial Inverse Force Histogram combined with Max-Min Boundary
}

\author{
Nattapong Songneam
}

\begin{abstract}
Sign language image recognition is also a very interesting research topic. Because it can be applied to help normal people understand and use it as a communication tool for the hearing impaired. The objectives of this research were to: 1) study and analyze Thai Sign Language image recognition image data for hearing impaired, 2) develop Thai Sign Language image recognition system for hearing impaired by using new techniques, and 3) measure the efficiency of Thai sign language image recognition for hearing impaired using Radial Inverse Force Histogram and the Maximum and Minimum boundary values. The results of the research were as follows: 1) The study and analysis of image data of Thai Sign Language Image Recognition In this research, 62,694 sign language images were used, divided into 2 parts: 1) American Sign Language images, which consisted of 36 groups of images, namely 26 groups of letters (AZ) and 10 groups of numbers (0-9), and Part 2) Picture of Thai Sign Language consisting of 61 groups of images, including 44 groups of letters (n-ฮ), 7 groups of vowels and 10 groups of numbers (0-9). Each group of pictures is rotated, enlarged, and Image promotion There were 6 sub-groups of images in various forms, divided into 2 parts: $70 \%$ of the images for training and $30 \%$ of the images for testing. 3) The results of measuring the efficiency of image recognition. It is divided into two parts: American Sign Language Image Recognition and Thai Sign Language Image Recognition. Compared with the Angular histogram method, the mean image accuracy was 0.86 , the recall of the mean American sign language was 0.91, and the accuracy of the Thai Sign Language was 0.78 . The recognition performance for Thai Sign Language images averaged 0.89 , while the recognition efficiency was achieved when using radial inverse force histograms in combination with image similarity measurements with maximum-minimum boundary values. Accuracy for Mean American Sign Language was 0.99 and Remembrance for Mean American Sign was 1.00, while Accuracy for Mean Thai Sign Language was 0.89. Mean Remembrance for Thai Sign Language was 0.96. The results of the visual recognition performance measurement of both the American Sign Language and the Thai Sign Language images were very good compared to the Angular Histogram method.

Keywords: Image Recognition, Thai Sign Language, American Sign Language, Hearing-Impaired, Radial Inverse Force Histogram, Maximum and Minimum Boundary Values
\end{abstract}

Manuscript received on June 19, 2021

Revised Manuscript received on June 25, 2021.

Manuscript published on June 30, 2021.

* Correspondence Author

Nattapong Songneam*, Department of Computer Science, Faculty of Science and Technology, Phranakhon Rajaphat University, Bangkok, Thailand. Email: xnattapong@hotmail.com

(C) The Authors. Published by Blue Eyes Intelligence Engineering and Sciences Publication (BEIESP). This is an open access article under the CC BY-NC-ND license (http://creativecommons.org/licenses/by-nc-nd/4.0/)

\section{INTRODUCTION}

Most people with disabilities face problems and have great difficulty in living in society. Due to different disabilities depending on the loss incurred by the visually impaired, lacking visual acuity, unable to tell the shape appearance and color. People with disabilities whose legs or arms are torn are unable to easily use their legs or arms to walk or lift heavy objects. As for people who are hearing impaired or "deaf", they lack the perception that they need hearing [5] People with disabilities can live their lives, do good deeds and contribute to society as normal people by using other things to replace the missing parts. For example, the hearing impaired will use sign language to communicate instead of speaking by normal people. They are unable to communicate by voice, both speaking and listening. [23] because deaf people cannot hear speech like normal people so they can't speak. Deaf people with normal eyesight can see gestures and movements. The images can be used to make deaf people learn meanings. Although they do not understand much but it is also part of the influence that drives deaf people to try to use gestures, bodies and facial expressions to express their inner feelings so that others can understand their needs. [6] The gestures shown are the ones that most mimic nature. From natural gestures have evolved, most of them use their hands to make gestures, resulting in gestures that can be used to represent the meaning of normal people's words. This developed gesture language is called sign language [20] Therefore, [18] if a hearing-impaired person wants to communicate, it is necessary to use sign language to communicate by agreeing symbols to have meanings that are understood by both the messenger and the receiver. [22] If you want to communicate with someone who doesn't know sign language, you must have a sign language interpreter. Sign language is most often used for the hearing-impaired group including the disabled, the interpreter (Interpreter), colleagues, friends, and family of people with disabilities using hand communication body communication and using lips instead of speaking. Communication will use the nature of the hand to symbolize. Movement of hands, arms, body, and facial expressions help to communicate the thoughts of the messengers [2] The recognition of such sign language is a special human ability that requires observing the gestures of the messenger, the characteristics of the hands, arms and faces, and then interpreting the symbols agreed upon and accepted by both the messenger and the receiver.

\section{Published By:}

Blue Eyes Intelligence Engineering and Sciences Publication

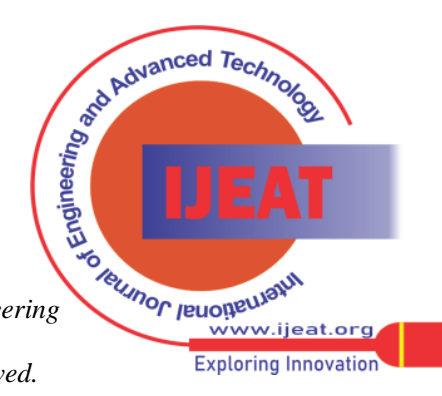


This capability is difficult for computers to observe and interpret like humans. [3] From the rapidly increasing advances in information technology and computers nowadays, it can create opportunities for people with disabilities or the disadvantaged from physical disabilities. There are innovations, creation of new applications for helping people with disabilities so that people with disabilities can develop knowledge skills and can help themselves causing the disabled to not be abandoned as a burden of society. [15] Image recognition research is still a popular topic of research in computer science and information technology because it can be applied in a variety of applications such as facial recognition of criminals, [12] registration of car license plates, predicting the nature of terrorists, etc. It can also be applied to the development of applications. More and more complex methods have been developed, for example, the Adaptive Neural Fuzzy Inference System which is one of the methods developed from knowledge of Artificial Neural Networks and Fuzzy Logic [8] data mining techniques, machine learning, and deep learning, etc.

At present, many new ideas and techniques have been proposed to solve problems by developing image recognition techniques and image retrieval techniques that use image characteristics such as shape, color, and texture of objects within the image. By storing and retrieving images, the system will extract the characteristics of each image in the database which will be in the form of a numeric value called Image feature to use as an image index for storing images in a database. [16] To retrieve images, user will select an inquiry image. The system will extract the characteristics of the query image to compare with the characteristics of the image in the database to retrieve images that are most similar the query image. To retrieve images The user will select an inquiry image. The system will then extract the characteristics of the query image to compare with the characteristics of the image in the database. to retrieve images that are most similar the query image. [17] Image recognition using the characteristics of the current image has developed techniques and methods. There are many ways to recognize images by image characteristics. [13] Each method has different advantages and disadvantages such as the use of a histogram technique of the distance between the center of the image (Centroid) and the edge of the image (Edge). The disadvantage of this method is the loss of a large amount of detail information within the object image. While these data are important for distinguishing images from one another, the efficiency of recognition is greatly reduced. To solve the problem, this research presents a new technique based on the concept of Newton's Theory of Gravity Applied for the extraction of features of objects (Feature extraction) called "Radial Inverse Force Histograms". [19] The radial inverse force can be calculated from the force of attraction between the mass of the image point at the image's center of gravity and all image points in the object's image. [9] This makes it possible to reduce the loss of image data and have better performance than the old method. [14] By this technique, there is a research hypothesis that each image of an object has a different attraction between the masses within the object image. This can make it possible to distinguish between objects and images clearly and effectively. [11]
Therefore, sign language recognition is a very interesting research topic as the success of this research can be applied to help normal people understand sign language images and communicate with the hearing impaired initially. The principles of image recognition and image processing were analyzed to create applications to facilitate communication with sign language instead of voice. [10] In this research, sign language recognition is used to analyze hand and finger gestures to interpret the meaning of sign language symbols by spelling letter-by-letter and numbers 0-9 using various image processing techniques. The analysis enabled computers to recognize images of Thai sign language with spelling numbers 0-9 and Thai [21] to help the hearing impaired. This research aims to develop a sign language recognition system for the hearing impaired of Thai people.

At the beginning of this research, knowledge and theories related to Image Classification System [1] were studied by studying Chain code theory as a guideline to develop a new technique for distinguishing image characteristics. (The process of isolating the characteristics of an image is one of the important steps in the image retrieval system.) Subsequently, an edge reduction technique was developed using the Reduced Coefficient of Elliptic Fourier Descriptors [4] to find out the characteristics of the image with the shape boundary and to measure the similarity of the image by the Membership Matching Score method [7] This way the images can be separated and work to a certain extent, but there is also a downside because this method only works on the edges of the image when in reality the details within the image are considered important parts of the image.

\section{EQUIPMENT AND METHODOLOGY}

\section{A. Data Set}

The image data set used in the experiment were divided into two parts: 1) American Sign Language Image Recognition and 2) Thai Sign Language Image Recognition. It will use standard images from internet resources of 62,694 images.

1. The training data set consisted of 43,886 images, representing $70 \%$ of the total images.

2. The test data set consisted of 18,808 images, representing $30 \%$ of the total.

\section{B. Software and Tools}

In this research used Visual Basic.net, 2) MS-SQL Server, and 3) Rapid Miner Studio

\section{Research Methodology}

In conducting research on American Sign Language images recognition and Thai Sign Language images experimental, it is divided into 2 main parts as follows: 1) American Sign Language image recognition experimental, and 2) Thai Sign Language images recognition experimental.

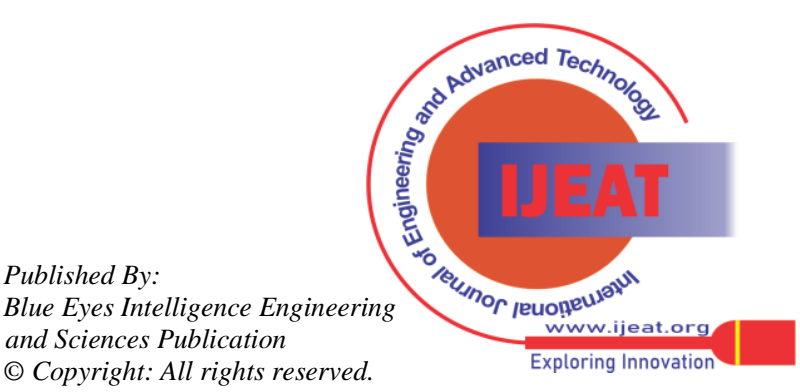




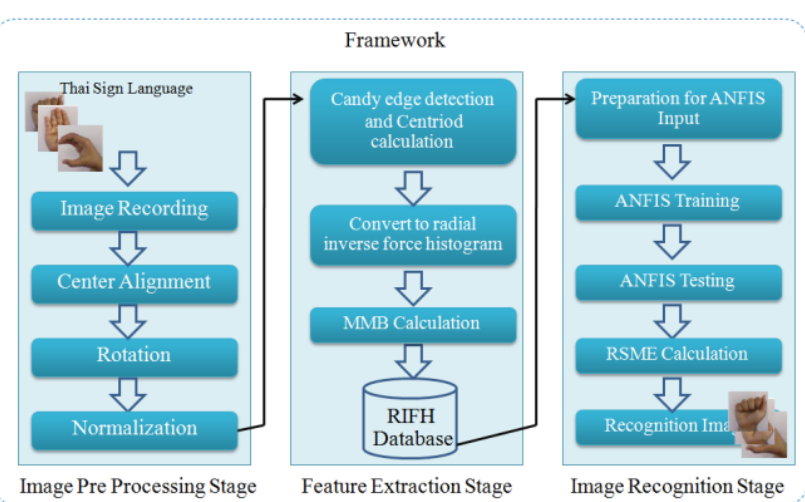

Fig. 1. Research Framework.

From Figure 1. It is the conceptual framework of this research project divided into 3 parts as follows:

Part 1. Image data preparation and image processing In this step, sign language images are prepared. Then have to go through image adjustments first, such as the subject of light, shadow, noise, image size, image rotation, which is to adjust the image to make it better or adjust it to be in the same format.

Part 2. Finding the Characteristics of an Image At this stage, the method of characterization of the image was chosen using histogram of radial inverse forces. The maximum and minimum extent of the radial inverse force histogram are calculated and recorded in the database to prepare for the next step.

Part 3. Image recognition by taking the histogram of radial inverse forces stored in the database to prepare as input data to input and then practice (Training). and testing (Testing) to identify the desired image values.

\section{Step 1: Images Preparation}

1. American Sign Language and Thai Sign Language image recognition experiment, It uses standard images from Internet resources and for image recognition, 62,694 images are used in the experiment, divided into 62,694 images used for training data set and images for testing. 6,269 images (10\% of the images used in the training)

2. Define a subgroup the experiment in this section is a test to determine the optimal size of image groups to be used as a training image to determine how many images of each group of images for training should be used to produce the best recognition results. image By dividing the images of every group of images into 6 groups of images together, then measure the accuracy (Precision) and the recall (Recall) with the details as follows.

The first subgroup is rotated by 1 degree to get all the images in this group of 360 images.

The second subgroup is rotated by 2 degrees to get all 180 images in this group.

The third subgroup is rotated by 4 degrees to get all 90 images in this group.

The fourth subgroup is rotated by 8 degrees to get all 45 images in this group.

The fifth subgroup is rotated by 10 degrees to get all 36 images in this group.

The sixth subgroup is rotated by 20 degrees increments to get all 18 images in this group.

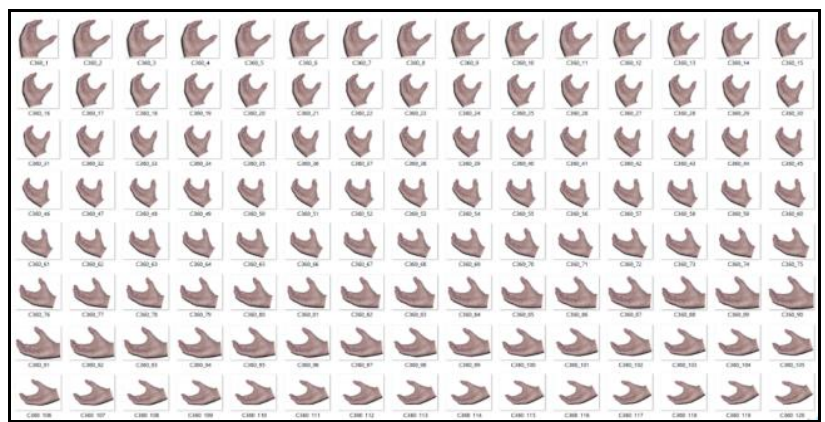

Fig. 2. Example of $\mathrm{C}$ alphabet is rotating 1-degree increments.

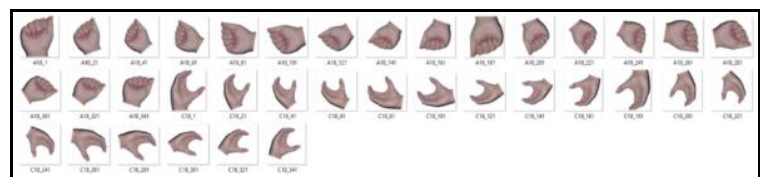

Fig. 3. Example of $\mathrm{C}$ alphabet is rotating 20-degree increments.

Table-1: Example of sub class

\begin{tabular}{|c|c|c|}
\hline No & Sub Class & Thai Sign Images \\
\hline 1 & $\begin{array}{l}\text { ก_trn_18 } \\
\text { ก_trn_36 } \\
\text { ก_trn_45 } \\
\text { ก_trn_90 } \\
\text { ก_trn_180 } \\
\text { ก_trn_360 }\end{array}$ & ก \\
\hline 2 & $\begin{array}{l}\text { ข_trn_18 } \\
\text { ข_trn_36 } \\
\text { ข_trn_45 } \\
\text { ข_trn_90 } \\
\text { ข_trn_180 } \\
\text { ข_trn_360 }\end{array}$ & ข \\
\hline 3 & $\begin{array}{l}\text { ค_trn_18 } \\
\text { ค_trn_36 } \\
\text { ค_trn_45 } \\
\text { ค_trn_90 } \\
\text { ค_trn_180 } \\
\text { ค_trn_360 }\end{array}$ & 1 \\
\hline 4 & $\begin{array}{l}\text { ง_trn_18 } \\
\text { ง_trn_36 } \\
\text { ง_trn_45 } \\
\text { ง_trn_90 } \\
\text { ง_trn_180 } \\
\text { ง_trn_360 }\end{array}$ & \\
\hline$\ldots$ & $\ldots$ & \\
\hline 44 & $\begin{array}{l}\text { ฮ_trn_18 } \\
\text { ฮ_trn_36 } \\
\text { ฮ_trn_45 } \\
\text { ฮ_trn_90 } \\
\text { ฮ_trn_180 } \\
\text { ฮ_trn_360 }\end{array}$ & \\
\hline
\end{tabular}

Published By:

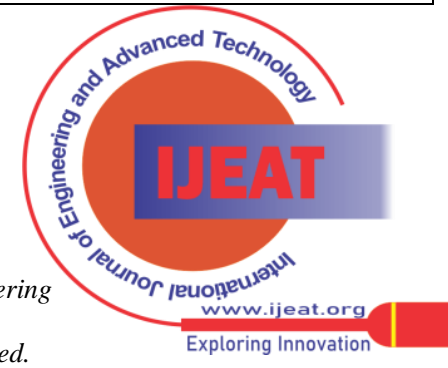




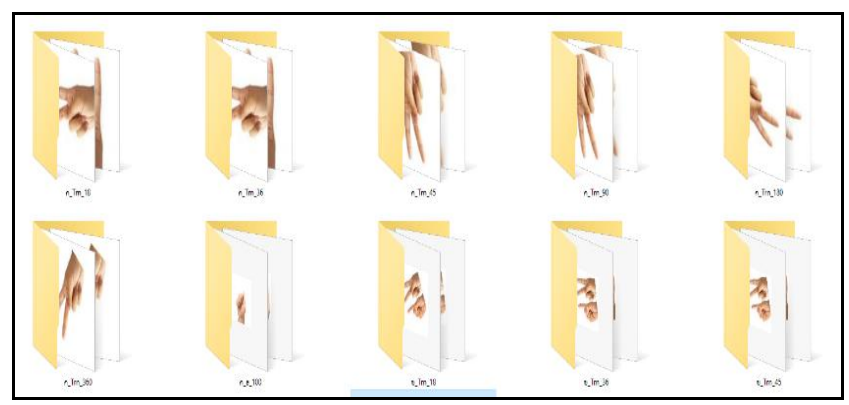

Fig. 4. Example subclass of Alphabet(n).

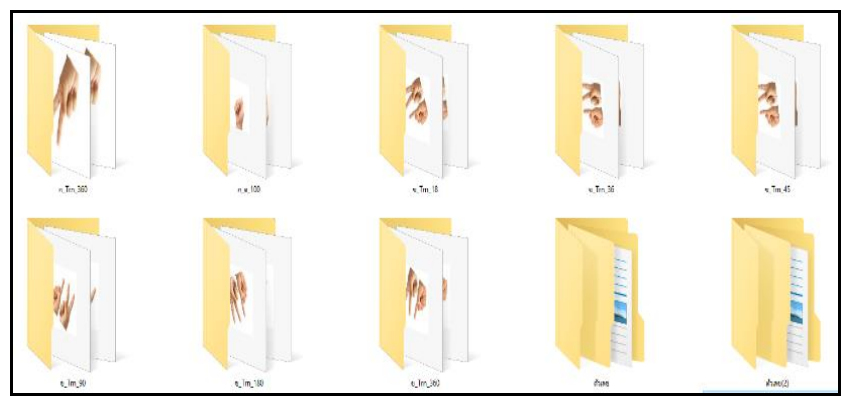

Fig. 5. Example subclass of Alphabet(v).

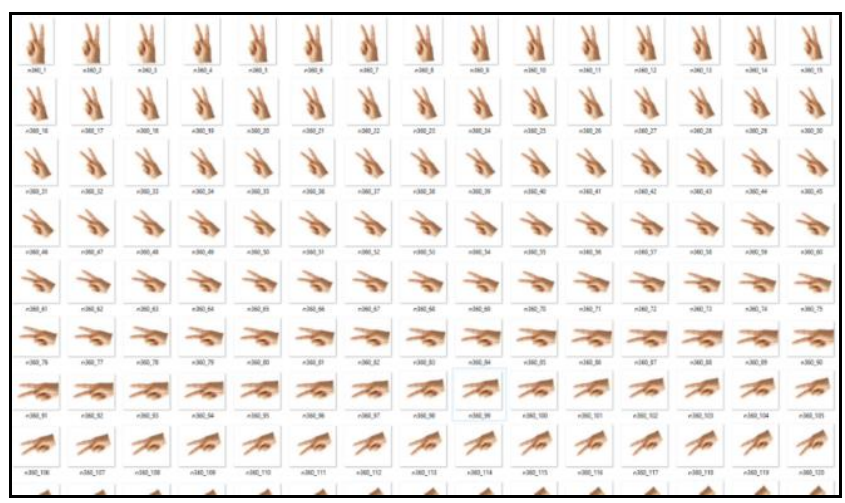

Fig. 6. The example of group of images "ก_trn_360"

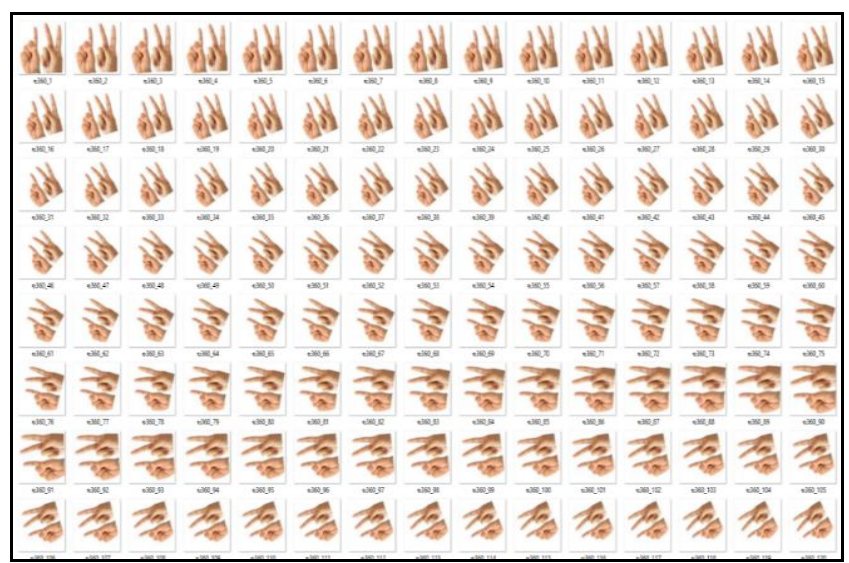

Fig. 7. The example of group of images "v_trn_360"

\section{Step 2: Feature Extraction}

To analyze the function of the image recognition system. with the structure of the image recognition system as shown in Figure 8.

From Figure 8, the main steps can be divided into 2 parts as follows:

Part 1, the training stage (Training Stage) is a step that takes all images to find the characteristics of the image in the form of Radial Inverse Forces Histogram (RIFH), then bring the value of the histogram of the Radial Inverse Force of the image group was calculated for the maximum-minimum boundary and then recorded in the database.

Part 2, the retrieval stage is the process of retrieving the image by converting it into a histogram of inverse forces and comparing it with the highest-lowest boundary of the image group. already in the database and then display of the retrieved images arranged in order of the most similar or similar the query image.

\section{Image Recognition Procedure Analysis}

At this stage, the workflow is analyzed to determine the sign language algorithm or image recognition algorithm. In this research, image recognition is divided into two parts: 1 ) grayscale image recognition and 2) color image recognition. There are algorithms for image recognition as follows.

image recognition working process There are steps as follows.

1) Read the sign language images used for training into the system.

2) Separate the characteristics of the training image (Feature Extraction) by

2.1) Calculate the center of gravity of the image.

2.2) Calculate the radial force

2.3) Calculate the image rotated to different angles and rotate the image to the starting angle.

2.4) Calculate the histogram of radial inverse forces.

2.5) Calculate the moving average of the histogram of radial inverse forces.

3) Calculate the maximum-minimum boundary of the moving average of the histogram of radial inverse forces for each image group.

4) Store the data of the maximum-minimum boundary of the moving average histogram of radial inverse forces representing each group of images in the database.

5) To retrieve it, read the image used for testing in.

6) Distinguish the characteristics as well as the pictures used for teaching (dos 2.1- no. 2.5).

7) Perform a similarity measurement of the query image with the image in the database using the technique of the maximum-minimum boundary of the moving average of the histogram of radial inverse forces.

8) Then you will get the image that you want to recognize.

Can be written as a flowchart of sign language image recognition as shown in figure 9 .
Published By:

Blue Eyes Intelligence Engineering and Sciences Publication

(C) Copyright: All rights reserved.

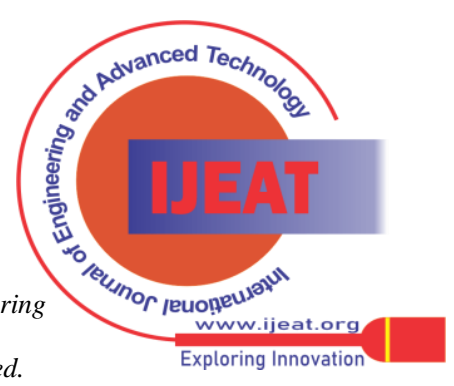




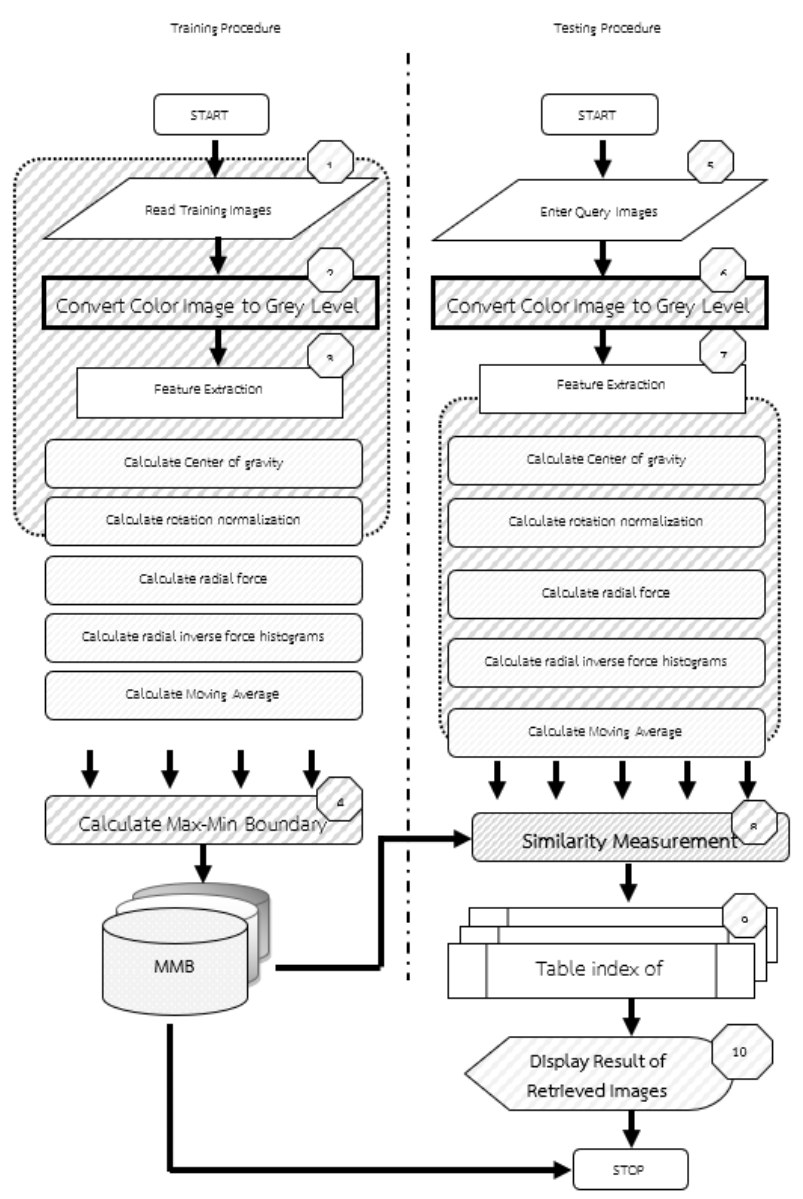

Fig. 8. RIFH Image Recognition Flowchart.

From Figure 8. the steps in the flowchart can be explained in detail as follows.

1) Sign Language Images Reading

In this research, all images have been prepared in step 1 to be used as both training images and testing images. which has been stored on the computer since the image data is prepared the program user can click on the button to read the image and select the desired image. The program will then process the images and convert the images into training data and store them in a database.

\section{2) Feature Extraction}

Feature Extraction is one of the most important steps in image recognition. Because it is a step that must find the characteristics of the image in order for the system to be able to distinguish each image from each other. The characteristics of the images in the same group must be similar or similar, but if the images are not in the same group, there will be different characteristics of the images. In this research, a new method for distinguishing image characteristics known as "Histogram of radial inverse forces" which will have different working processes as detailed below.

3) Feature Extraction using RIFH (RIFH: Radial Inverse Force Histograms)

To distinguish the characteristics of the images used in this research, both grayscale and color images were used. Newton's Theory of Gravity Applied to separate the characteristics of the image (Feature Extraction) by assuming that the image point represents the mass of the object, which each image point in the same image will have an attraction between them. It only pays attention to the force of attraction between the image points in the image of any object along the same radius or angle acting on the image point at the center of gravity of the object image. Then find the sum of all the forces in the same radial direction. as detailed in Figure 9.

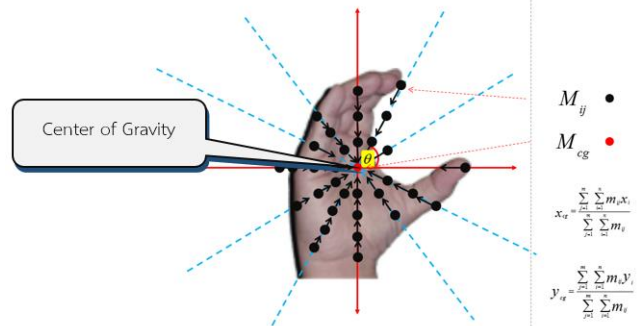

Fig. 9. Radial inverse force image of an object image.

4) Finding the Center of Gravity of an object

Finding the center of gravity of any object image can be calculated from the equation (1) as follows:

$$
x_{c g}=\frac{\sum_{j=1}^{m} \sum_{i=1}^{n} m_{i j} x_{i}}{\sum_{j=1}^{m} \sum_{i=1}^{n} m_{i j}} \quad y_{c g}=\frac{\sum_{j=1}^{m} \sum_{i=1}^{n} m_{i j} y_{i}}{\sum_{j=1}^{m} \sum_{i=1}^{n} m_{i j}}
$$

Given by:

$$
\boldsymbol{X}_{c g}, \boldsymbol{Y}_{c g} \text { is the coordinating point of the center of }
$$
gravity,

$m_{i j}$ is the grayscale of the image point at the i row, column $\mathrm{j}$,

$X_{i}$ is the axial distance between the center of gravity and the image point at the position,

$y_{i}$ is the axial distance between the center of gravity and the image point at the position,

$m$ is the number of rows,

$n$ is the number of columns,

$j$ is the order of the rows (index of rows),

$i \quad$ is the order of the columns (index of columns).

An example of calculating the center of gravity of an image of object A with grayscale values is shown in the table below.

\begin{tabular}{|l|l|l|l|l|}
\hline 20 & 10 & 20 & 30 & 40 \\
\hline 40 & 30 & 20 & 10 & 200 \\
\hline 100 & 100 & 50 & 100 & 80 \\
\hline 30 & 100 & 100 & 90 & 80 \\
\hline
\end{tabular}

$x_{c g}=((20 * 1)+(10 * 2)+(20 * 3)+(30 * 4)+(40 * 5)+(40 * 1)+(30 * 2)+(20 * 3)(10 * 4)+(200 * 5)+$ $\begin{aligned} & (100 * 1)+(100 * 2)+(50 * 3)+(100 * 4)+(80 * 5)+(30 * 1)+(100 * 2)+(100 * 3)+(90 * 4)+ \\ & (80 * 5)) /((20+10+20+30+40+40+30+20+10+200+100+100+50+100+80+30+100+100+90+80))\end{aligned}$ $=6460 / 1250$
$=5.17$

$y_{c g}=((20 * 1)+(40 * 2)+(100 * 3)+(30 * 4)+(10 * 1)+(30 * 2)+(100 * 3)+(100 * 3)+$ $(20 * 1)+(20 * 2)+(50 * 3)+(100 * 4)+(30 * 1)+(10 * 2)+(100 * 3)+(90 * 4)+$ $(40 * 1)+(200 * 2)+(80 * 3)+(80 * 4)) /((20+10+20+30+40+40+30+20+10+200+$ $00+90+80))$ $=3610 / 1250$
$=2.8$ Blue Eyes Intelligence Engineering and Sciences Publication 
So, point $\boldsymbol{X}_{c g}$ and $\boldsymbol{Y}_{c g}$ are $(5,3)$ due to rounding up and down.

5) Calculation of Radial force

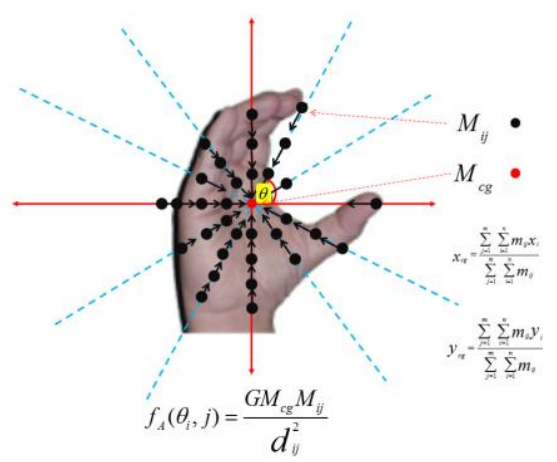

Fig. 10. Calculation of Radial force at any $\Theta$ degree.

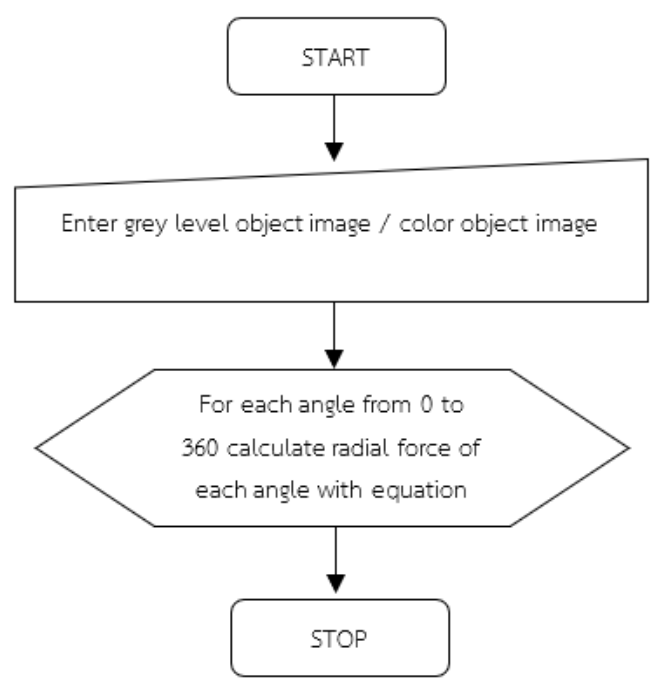

Fig. 11. Calculation of the radial force of any object image flowchart.

\section{6) Radial force}

Radial force $f_{A}\left(\theta_{i}, j\right)$ is the value of the attraction force between the mass of the image spot located at the gravity center of the image and the values of the image point located at various radial positions at any angle $(\Theta)$. This radial line is obtained from equation (2).

$$
f_{A}\left(\theta_{i}, j\right)=\frac{G M_{c g} M_{i j}}{d_{i j}^{2}}
$$

Given by:

$f_{A}\left(\theta_{i}, j\right)$ is the force between the image points at $j$ in the angle $\theta_{i}$,

$\theta_{i}$ is the angles of $i$ where $i$ is between 0 and 360 degree,

$j$ is the radial position of the image point, where $j$ is between 1 and the final position on the periphery,
$G$ is the universal gravitational constant of the gravitational force between the masses which is equal to $6.67 \times 10^{-11} \mathrm{~N}-\mathrm{m}^{2} / \mathrm{kg}^{2}$,

$d_{i j}^{2}$ is the square of the distance from the image point to the center of gravity to the position of any image point in a radius,

$M_{c g}$ is the imaginary mass of the image point located at the center of gravity of the image, In this research, the value is set to 1 ,

$M_{i j}$ is the hypothetical mass of the image point located at any point along the radius of the picture The image level is between $0-255$ and the color object image has the RGB value.

Considering equation (2), the form of the equation can be reduced to make it easier to calculate by

Setting

$$
\begin{array}{ll}
G & \text { is equal to } 1 \text { and, } \\
M_{c g} & \text { is equal to } 1 .
\end{array}
$$

This will result in a new equation as follows:

$$
f_{A}\left(\theta_{i}, j\right)=\frac{M_{i j}}{d_{i j}^{2}}
$$

Therefore, the histogram of radial forces $F_{A}\left(\theta_{i}\right)$ is obtained by the sum of all forces in the same radial direction.

$$
F_{A}\left(\theta_{i}\right)=\sum_{j=1}^{n} f_{A}\left(\theta_{i}, j\right)
$$

Given by:

$F_{A}\left(\theta_{i}\right)$ is the histogram of radial forces,

$A$ is any object image.

7) Radial Inverse Force Histograms

From Equation 3, it is found that the value of force $F_{A}\left(\theta_{i}\right)$ is proportional to the distance (Distance) between the radial image point and the image point located at the center of gravity of the image. The image point that is closer to the center of gravity of the image has a greater value of force $F_{A}\left(\theta_{i}\right)$ than the image point farther away. (This is a natural characteristic of gravity: the farther apart the masses, the lower the cost of labor.)

Published By:

Blue Eyes Intelligence Engineering and Sciences Publication

(C) Copyright: All rights reserved.

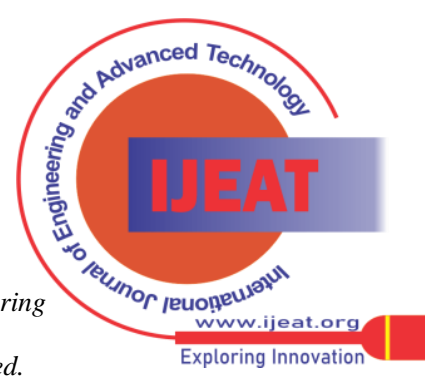


In fact, an image point further from the image's center of gravity is more important in characterizing the image than an image point closer to the image's center of gravity because it can be used to better describe the shape of an object image. Therefore, in order to solve this problem, in this research, the inverse of the forces at each image point was reversed and called this new technique. "Radial Inverse Force Histograms", which can be rewritten as follows:

$$
\gamma_{A}\left(\theta_{i}\right)=\sum_{j=1}^{n} \frac{1}{f_{A}\left(\theta_{i}, j\right)}=\sum_{j=1}^{n} \frac{d_{i j}^{2}}{M_{i j}} \quad i=1,2,3, \ldots, 360
$$

Given by:

$$
\begin{array}{ll}
\gamma_{A}\left(\theta_{i}\right) & \text { is the radial inverse force, } \\
A & \text { is any object image, } \\
\theta_{i} & \text { is any angle. }
\end{array}
$$

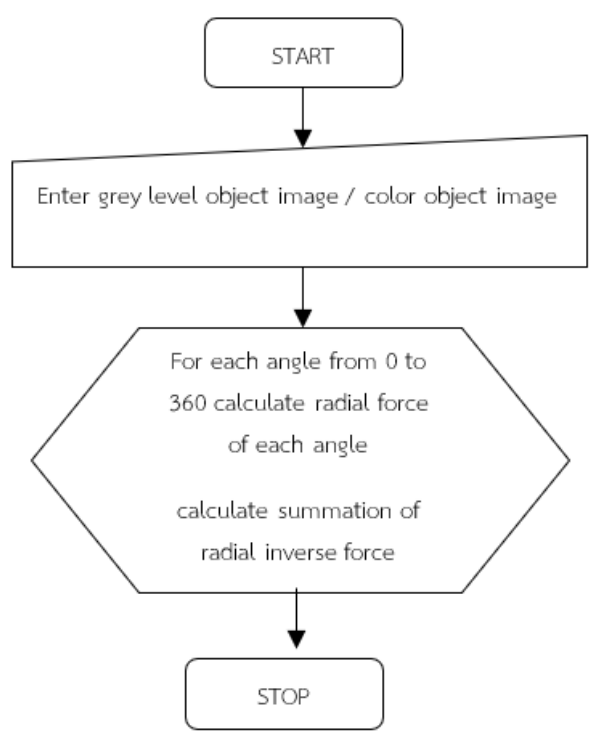

Fig. 12. Radial inverse force calculation flowchart

\section{8) Moving Average Calculation}

Considering the value of the radial inverse force calculated from Equation (5), it is found that the resulting value has fluctuations. When applied to real-world applications it can sometimes lead to disadvantages in image retrieval, which can result in reduced retrieval performance. Therefore, a moving average technique has been applied to solve this problem, which will smooth the resulting chart. This moving average can be calculated from Equation (6).

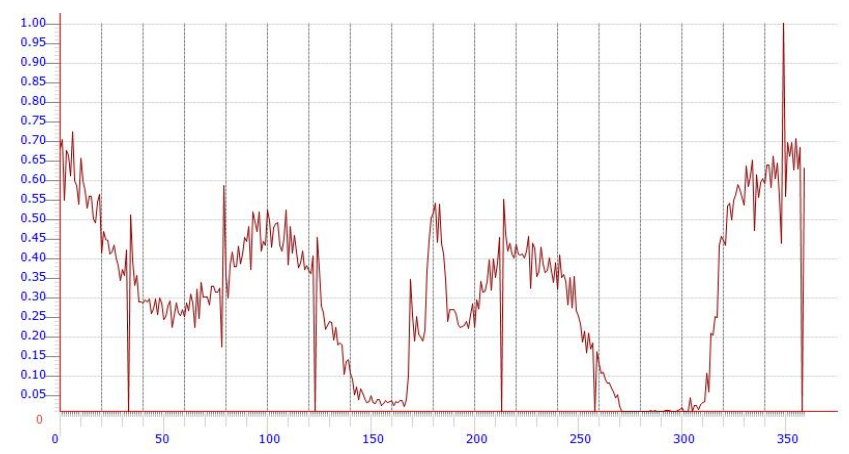

Fig. 13. Examples of radial inverse forces

$$
\bar{\gamma}_{A}\left(\theta_{i}\right)=\frac{\gamma_{A}\left(\theta_{i=i}\right)+\gamma_{A}\left(\theta_{i=i+1}\right)+\ldots+\gamma_{A}\left(\theta_{i=i+N-1}\right)}{N}, \quad i=1,2,3, \ldots n
$$

Given by:

$\gamma_{A}\left(\theta_{i}\right)$ is the $i^{\text {th }}$ position of the Radial Inverse Force Histogram,

$i$ is the order of the data,

$\mathrm{n} \quad$ is the last position of $i^{\text {th }}$,

$N$ is the range of numbers. (In this research, the value $\mathrm{N}$ $=10$ ).

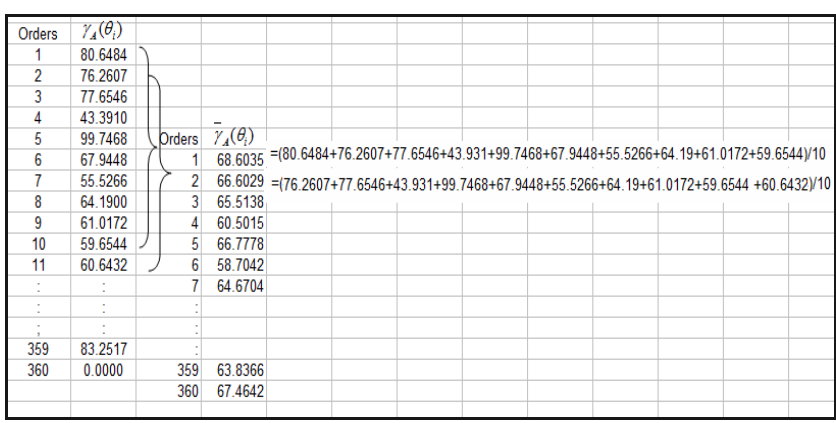

Fig. 14. Example of moving average line calculation $\bar{\gamma}_{A}\left(\theta_{i}\right)$

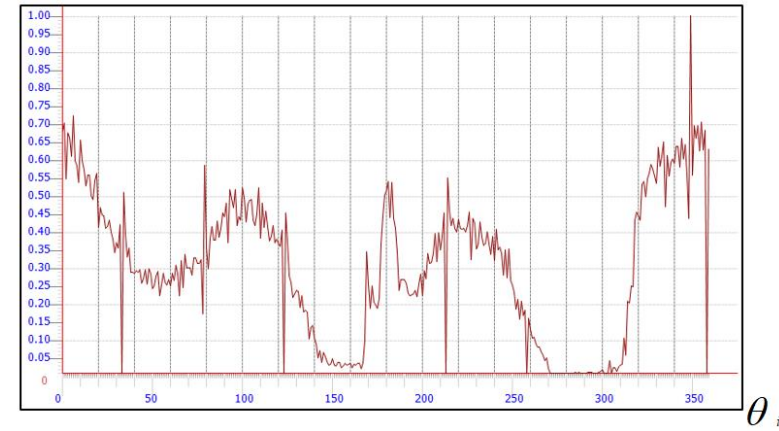

Fig. 15. Example of the radial inverse force is not calculating the moving average.

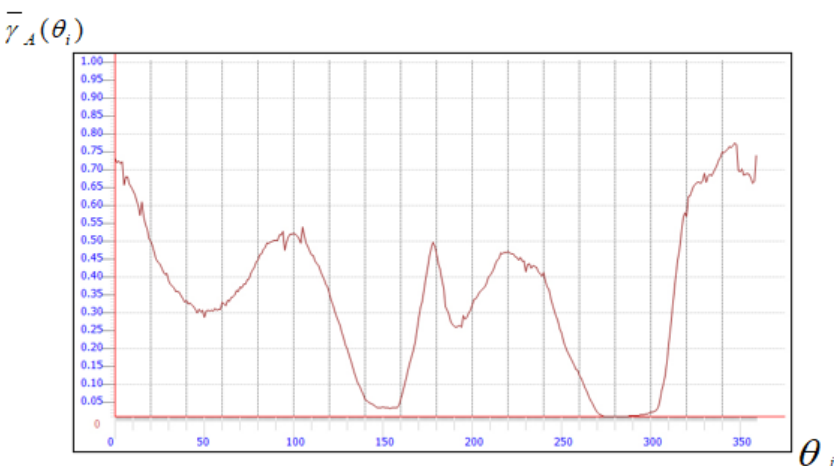

Fig. 16. Example of radial inverse force after moving average calculation.

9) Converting radial inverse forces to a histogram of radial inverse forces

\section{Published By:}

Blue Eyes Intelligence Engineering

and Sciences Publication

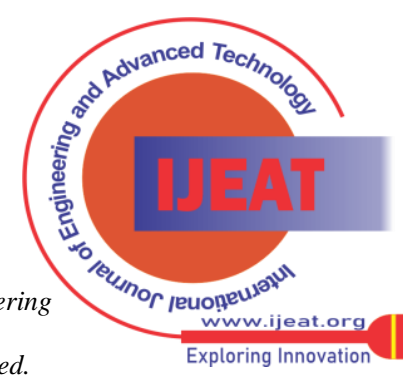


The histogram of radial inverse forces $\left(\bar{\gamma}_{A}\left(\theta_{i}\right)\right)$ is a graph showing the relationship between radial inverse forces acting on angles within an object image by creating a histogram of radial inverse forces. This can be done by assigning the horizontal axis to the value of the angle starting from angle 0 to the angle of 360 degrees. On the vertical axis, the value of the force acting on the angles is defined as the value of the force acting on the angles.

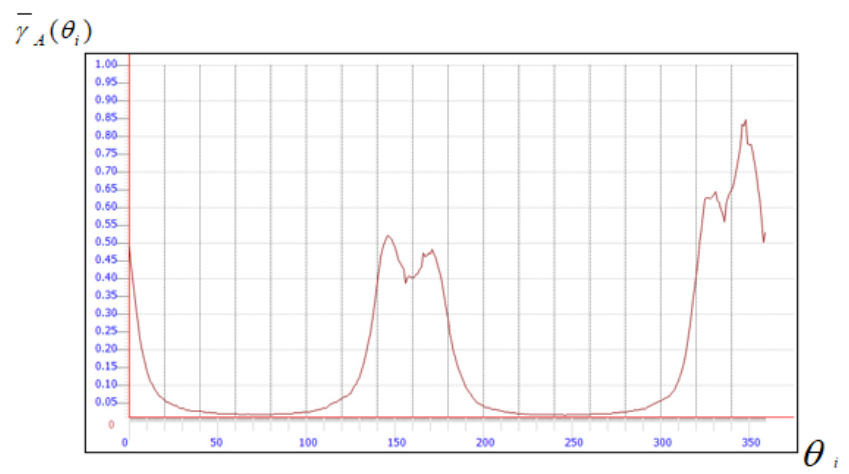

Fig. 17. Example of a Radial Inverse Force Histogram

10) Max-Min Boundary calculation

Max-Min Boundary is a technique in this research to be used for measuring the similarity or compatibility between histograms of radial inverse force of any two object images. It can be calculated from the highest and lowest values of each position of the histogram and counts the membership between the highest and lowest values of the histogram. If the membership counted is large, then the two images are very close. But if the value is less, it means that the two images are not similar or are different groups of images. In principle, Maximum-Minimum Boundary can be calculated using the following algorithm.

11) Research operations for image retrieval of colored objects

For the process of retrieving the color object image. The color object image that is used must be converted to grayscale by image processing method first. Then do all the steps as with the grey scale image.

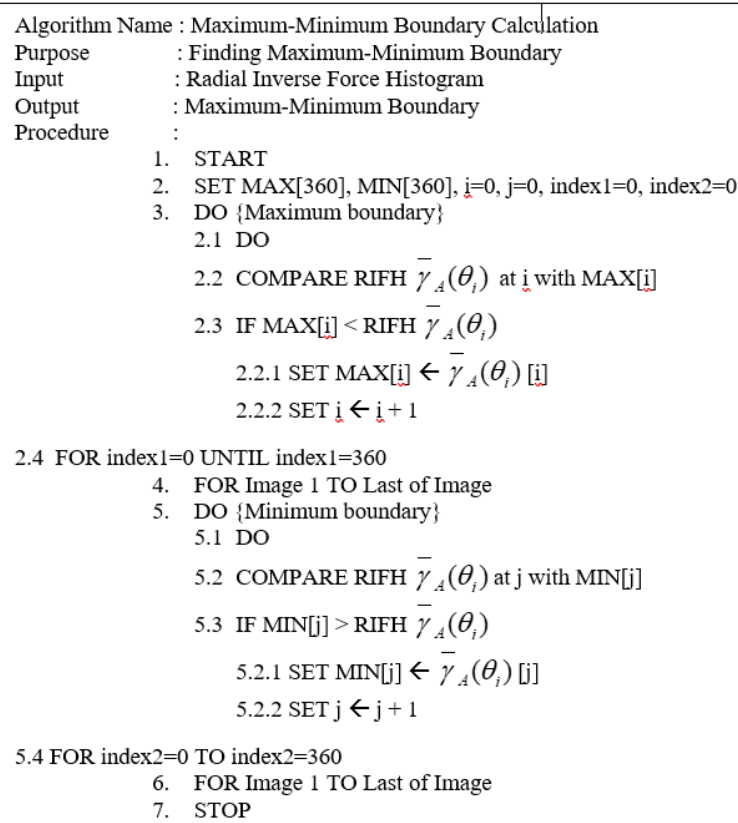

Fig. 18. Algorithm for calculating the maximum minimum boundary value.

The workflow of color image retrieval includes the following steps:

1) Read color object images (Color Object Images) used for training into the system.

2) Convert the color object image to grayscale object image by image processing method.

3) Separate the characteristics of the training image (Feature Extraction) by

3.1) Calculate the center of gravity of a colored object image.

3.2) Calculate the radial force

4) To retrieve it, read the image used for testing in.

5) Distinguish the characteristics as well as the pictures used for teaching (dos 3.1- 3.4).

6) Measure the similarity (Similarity Measurement) of the query image with the image in the database with the technique of maximum - minimum boundary values (MMB: Max-Min Boundary).

7) Then the retrieved image will be obtained in order of similarity of the retrieved image to the query image.

\section{RESULTS AND DISCUSSION}

\section{A. Experimental Result}

The experimental result was divided into two parts: 1) American Sign Language image recognition and 2) Thai Sign Lange image recognition. By using standard images from internet sources of 62,694 images, divided into 43,886 images used for training (Training Data Set), representing $70 \%$ of the total images, and images for testing (Testing Data Set) of 18,808 images, representing $30 \%$ of images used in training) as detailed in Table 1.

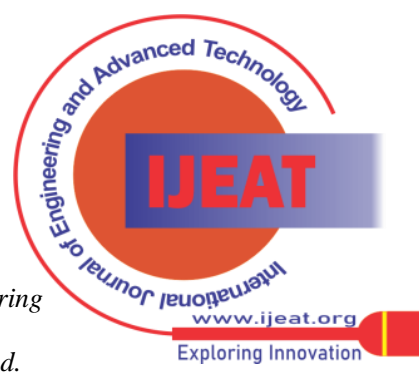


Table-2: Show number of data set.

\begin{tabular}{|c|c|c|c|c|c|c|c|c|}
\hline No. & List & subgroup 1 & subgroup 2 & subgroup 3 & subgroup 4 & subgroup 5 & subgroup 6 & Total \\
\hline 1 & A-Z & 9,360 & 4,680 & 2,340 & 1,170 & 936 & 468 & 18,954 \\
\hline 2 & n-a & 15,840 & 7,920 & 3,960 & 1,980 & 1,584 & 792 & 32,076 \\
\hline 3 & กระ & 2,520 & 1,260 & 630 & 315 & 252 & 126 & 5,103 \\
\hline 4 & ตัวเข & 3,240 & 1,620 & 810 & 405 & 324 & 162 & 6,561 \\
\hline \multicolumn{7}{|c|}{ Total } \\
\hline
\end{tabular}

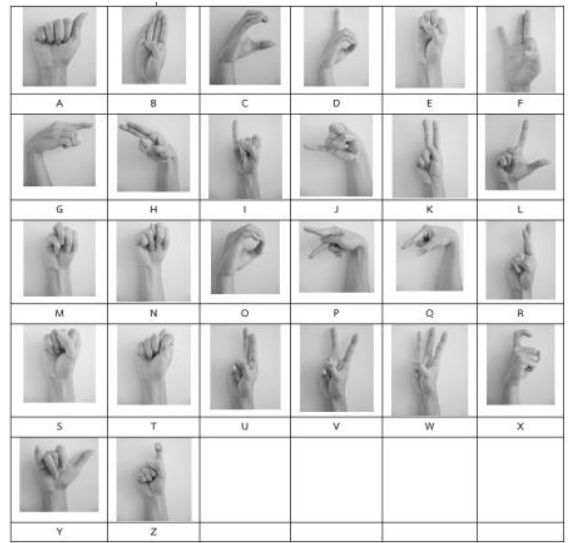

Fig. 19. American Alphabet

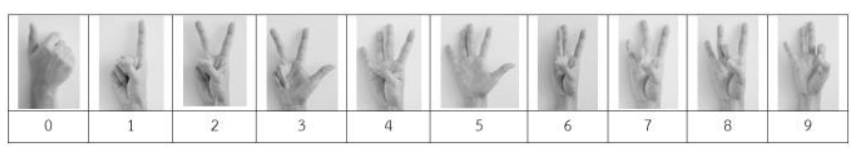

Fig. 20. American number.

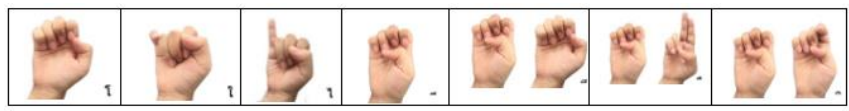

Fig. 21. Thai Sign Language (Vowels)

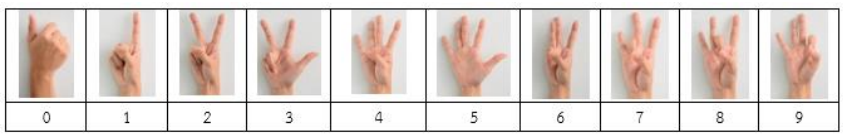

Fig. 22. Thai Sign Language (Number: 0-9)

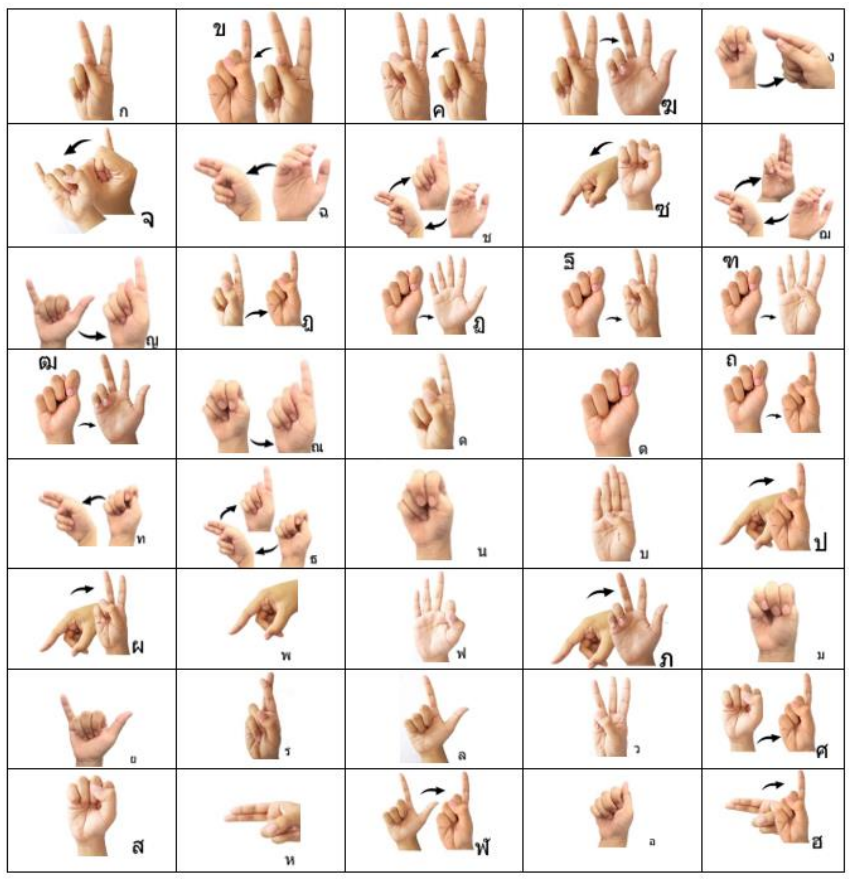

Fig. 23. Thai Sign Language (Alphabet ก-ฮ)
B. The result of image recognition for hearing-impaired software development

The example of converting the image to a Radial Inverse Force Histogram show as Fig 24 - Fig 26.

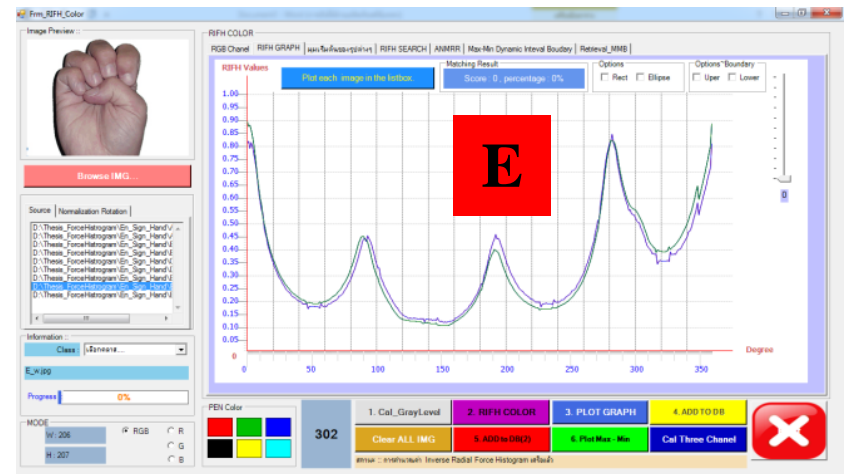

Fig. 24. Radial Inverse force Histogram of E (large size).

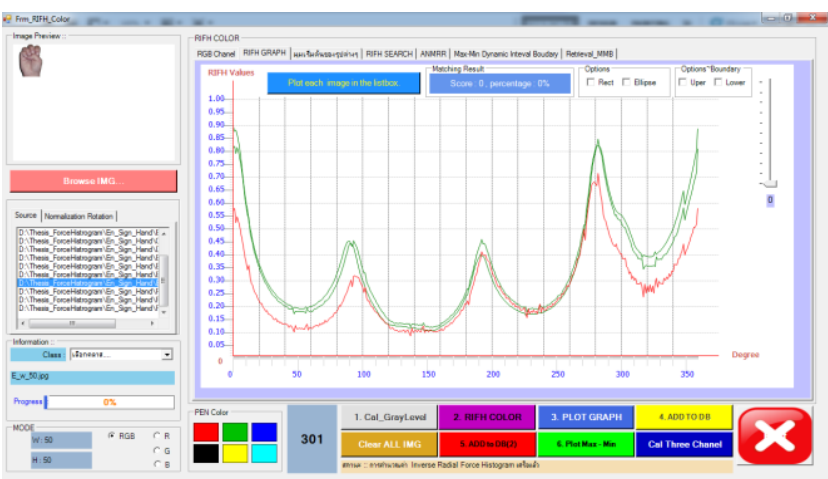

Fig. 25. Radial Inverse force Histogram of E (medium size).

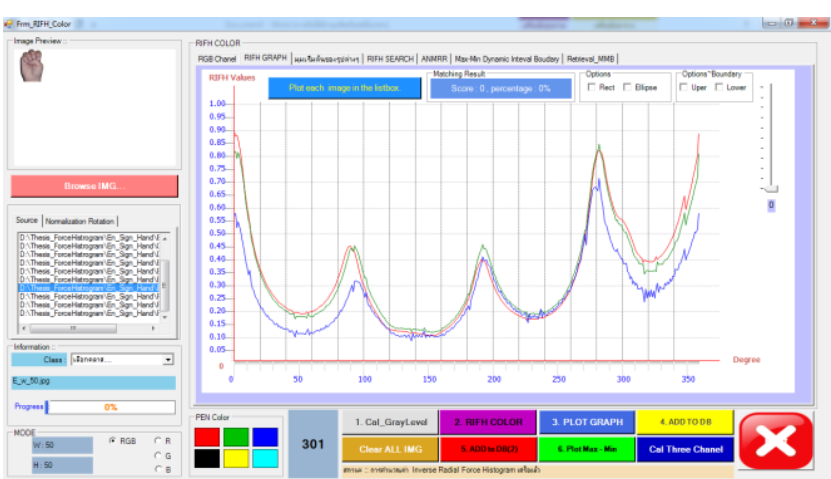

Fig. 26. Radial Inverse force Histogram of E (small size).
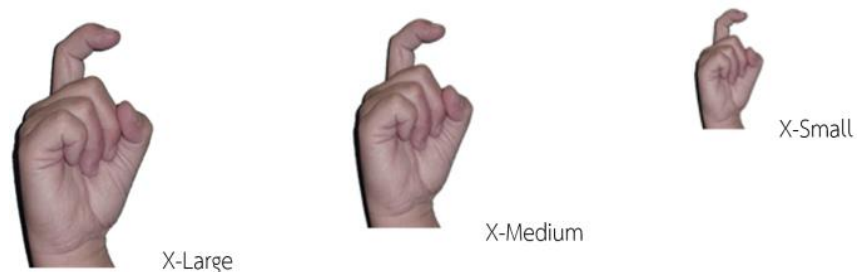

Fig. 27. Sign language image size type

Published By:

Blue Eyes Intelligence Engineering and Sciences Publication

(C) Copyright: All rights reserved.

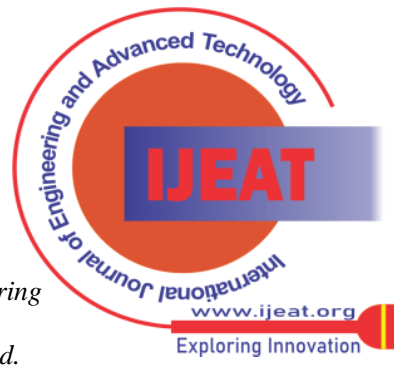


Thai Sign Language Image Recognition for the Hearing-Impaired using Radial Inverse Force Histogram combined with Max-Min Boundary

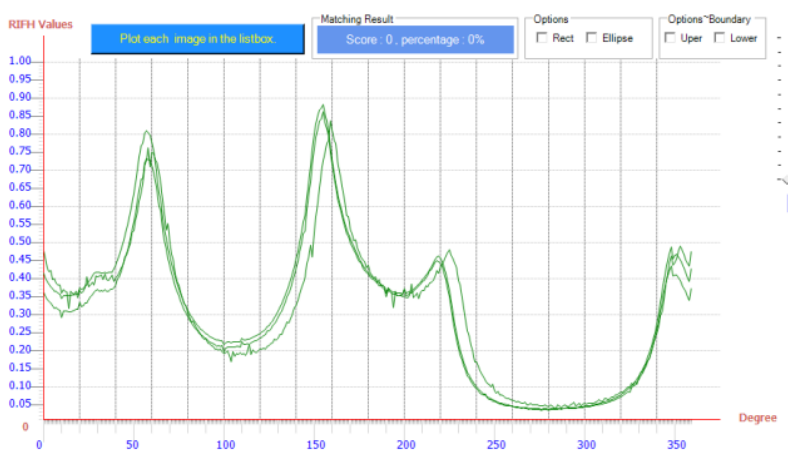

Fig. 28. RIFH values of $X$ sizes $X$-Large, $X$-Medium, $\mathrm{X}$-Small

\section{The result of performance and satisfaction assessment}

1) The result performance measurement of Recognition efficiency measures was divided into two parts: 1) American Sign Language Image Recognition and 2) Thai Sign Language Image Recognition. Compared with the Angular histogram method, the mean image accuracy was 0.86 , the recall of the mean American sign language was 0.91, and the accuracy of the Thai sign language was 0.78. Mean recognizability for Thai Sign Language images was 0.89 , while the Radial Inverse Force Histogram combined with image similarity measurement with Maximum-Minimum Boundary values has accuracy for Mean American Sign Language was 0.99 and Remembrance for Mean American Sign was 1.00 , while accuracy for mean Thai Sign Language was 0.89 . Mean Recall for Thai Sign Language was 0.96 . The results of the visual recognition performance measurement of both American Sign Language and Thai Sign Language images were very good compared to the other methods.

Table-3: Comparison of the times for each subgroup of calculations.

\begin{tabular}{|c|c|c|c|c|c|c|}
\hline $\begin{array}{c}\text { Number of } \\
\text { subgroups }\end{array}$ & $\mathbf{1}$ & $\mathbf{2}$ & $\mathbf{3}$ & $\mathbf{4}$ & $\mathbf{5}$ & $\mathbf{6}$ \\
\hline Number of Image & 360 & 180 & 90 & 45 & 36 & 18 \\
\hline & \multicolumn{6}{|c|}{ Time(second) } \\
\hline $\begin{array}{c}\text { Time of Radial } \\
\text { Inverse force } \\
\text { Histogram } \\
\text { calculation }\end{array}$ & 128.00 & 62.00 & 33.00 & 16.00 & 12.00 & 9.00 \\
\hline $\begin{array}{c}\text { Time of } \\
\text { Maximum-Minimum } \\
\text { boundary calculation }\end{array}$ & 2.00 & 1.90 & 1.80 & 1.40 & 0.98 & 0.89 \\
\hline Time of Recognition & 5.97 & 5.96 & 5.92 & 5.93 & 5.92 & 5.90 \\
\hline Total Time & $\mathbf{1 3 5 . 9 7}$ & $\mathbf{6 9 . 8 6}$ & $\mathbf{4 0 . 7 2}$ & $\mathbf{2 3 . 3 3}$ & $\mathbf{1 8 . 9 0}$ & $\mathbf{1 5 . 7 9}$ \\
\hline
\end{tabular}

Table-4: Summary of Image Recognition using Membership Matching Score Method with $\varsigma($ Sigma $)=5$

\begin{tabular}{|c|c|c|c|}
\hline No. & threshold (\%) & precision & recall \\
\hline 1 & 70 & 0.59 & 0.34 \\
\hline 2 & 80 & 0.51 & 0.28 \\
\hline 3 & 90 & 0.41 & 0.14 \\
\hline 4 & 100 & 0.31 & 0.05 \\
\hline
\end{tabular}

Table-5: Summary of Image Recognition using Membership Matching Score Method with $\varsigma($ Sigma $)=10$

\begin{tabular}{|c|c|c|c|}
\hline No. & threshold $(\%)$ & precision & recall \\
\hline 1 & 70 & 0.58 & 0.87 \\
\hline 2 & 80 & 0.69 & 0.70 \\
\hline 3 & 90 & 0.53 & 0.51 \\
\hline 4 & 100 & 0.44 & 0.08 \\
\hline
\end{tabular}

Table-6: Summary of Image Recognition using Membership Matching Score Method with $\varsigma($ Sigma $)=15$

\begin{tabular}{|c|c|c|c|}
\hline No. & threshold $(\%)$ & precision & recall \\
\hline 1 & 70 & 0.17 & 0.72 \\
\hline 2 & 80 & 0.50 & 0.73 \\
\hline 3 & 90 & 0.57 & 0.62 \\
\hline 4 & 100 & 0.48 & 0.28 \\
\hline
\end{tabular}

The results of the measurement of the efficiency of image recognition of Thai Sign Language using the highest-lowest boundary method. In this experiment, the image recognition was used to determine the size of the subgroups suitable for the size of the subgroups used for training. By using the same image for testing 18 images in all groups This will produce different results as detailed below.

Table-7: Compare the precision (Precision) of the image recognition for each group of images.

\begin{tabular}{|c|c|c|c|c|c|c|}
\hline \multirow{2}{*}{$\begin{array}{c}\text { Testing } \\
\text { Data } \\
\text { class }\end{array}$} & \multicolumn{6}{|c|}{ Precision } \\
\hline & $\begin{array}{c}\text { Subgroup } \\
\text { I }\end{array}$ & $\begin{array}{c}\text { Subgroup } \\
\text { II }\end{array}$ & $\begin{array}{c}\text { Subgroup } \\
\text { III }\end{array}$ & $\begin{array}{c}\text { Subgroup } \\
\text { IV }\end{array}$ & $\begin{array}{c}\text { Subgroup } \\
\mathrm{V}\end{array}$ & $\begin{array}{c}\text { Subgroup } \\
\text { VI } \\
\end{array}$ \\
\hline 355 & 100 & 98 & 87 & 66 & 44 & 44 \\
\hline น34 & 100 & 95 & 85 & 70 & 65 & 61 \\
\hline 440 & 100 & 98 & 89 & 75 & 67 & 63 \\
\hline จ67 & 100 & 97 & 90 & 74 & 68 & 62 \\
\hline ง80 & 100 & 100 & 92 & 85 & 76 & 70 \\
\hline ก97 & 100 & 96 & 86 & 82 & 74 & 69 \\
\hline «07 & 100 & 95 & 86 & 83 & 75 & 68 \\
\hline ส12 & 100 & 96 & 87 & 84 & 76 & 67 \\
\hline ช25 & 100 & 98 & 88 & 83 & 76 & 65 \\
\hline ด77 & 100 & 97 & 90 & 84 & 78 & 67 \\
\hline Avg & 100.00 & 97.00 & 88.00 & 78.60 & 69.90 & 63.60 \\
\hline
\end{tabular}

From Table 7. The images used in the test were randomly selected from all test images. It was found that the number of images for the training group influenced the accuracy of image recognition. If the number of images used for training is more, the accuracy of image recognition will increase accordingly. But if the number of shots used for coaching decreases, the accuracy and recall value will also decrease. At the same time, when considering the time required for image recognition, it was found that as the number of images used for training increases, the total time in image recognition also increases. The process of image recognition has the following steps:

Step 1. Calculation of the Radial Inverse Force Histogram.

Step 2. Calculation the Maximum-Minimum Boundary value

Step 3. Image Recognition.

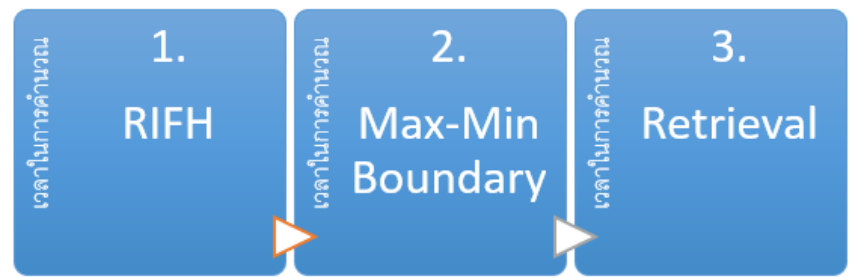

Fig. 29. Time spent on each step for training.

Published By:

Blue Eyes Intelligence Engineering and Sciences Publication

(C) Copyright: All rights reserved.

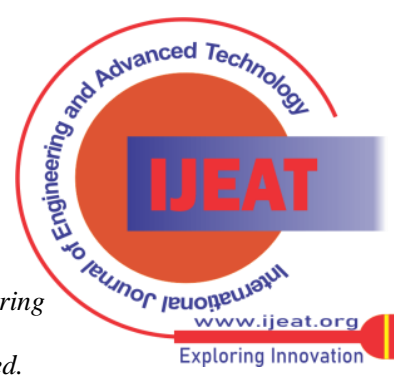


From Fig. 29. Show time spent on each step for training is Total time $=$ time to calculate Radial Inverse Force Histogram + time to calculate Maximum-Minimum Boundary value + time to recognize image.

Measuring the performance of image recognition using the Maximum-Minimum Boundary method with 20 experimental classes were sampled is $10 \%$ of all classes in the database, and each class. It was divided into two subclasses are class group that there are 18 and 36 images respectively detailed in Table 8.

Table-8: The result of image recognition using maximum-minimum boundary compared each threshold.

\begin{tabular}{|c|c|c|c|}
\hline No. & threshold (\%) & precision & recall \\
\hline 1 & 70 & 0.84 & 1.00 \\
\hline 2 & 80 & 0.96 & 1.00 \\
\hline 3 & 90 & 0.99 & 1.00 \\
\hline 4 & 100 & 0.95 & 0.82 \\
\hline
\end{tabular}

From table 8 the image recognition using the maximum-minimum boundary method with a threshold value of 90 yields, the precision is 0.99 , and recall is 1.00 , shows that image recognition using a $90 \%$ threshold is most effective when compared to other thresholds.

2) User satisfaction evaluation results, the results of the satisfaction assessment of the experimental use of the Sign Language Image Recognition Model Software from a sample group of 30 computer science students and 5 staff members of the Deaf Association of Thailand found that the students had knowledge and understanding. Using the sign language recognition system and overall satisfaction with the system is at a very good level This is because the system is designed to be easy to use and not complicated. As a result, the overall system efficiency is at a good level, in line with Chantira Sae-Tiao. The behavior of choosing mobile applications for middle-aged people the overall system performance test was at a good level and the satisfaction assessment results were compared according to the criteria shown in Table 9.

Table-9: Results of Satisfaction Assessment of Sign Language Image Recognition Prototype Software

\begin{tabular}{|l|c|c|c|}
\hline \multicolumn{1}{|c|}{ Topic } & $\bar{X}$ & S.D. & Result \\
\hline $\begin{array}{l}\text { 1. Screen design for Sign Language } \\
\text { Image Recognition Prototype }\end{array}$ & 4.56 & 0.44 & Very good \\
Software & & & \\
\hline $\begin{array}{l}\text { 2. The content of the Sign Language } \\
\text { Image Recognition Prototype } \\
\text { software }\end{array}$ & 4.55 & 0.86 & Very good \\
\hline $\begin{array}{l}\text { 3. In terms of using the Sign Language } \\
\text { Image Recognition Prototype } \\
\text { Software }\end{array}$ & 4.48 & 0.86 & good \\
\hline $\begin{array}{l}\text { 4. The overall of the sign language } \\
\text { image recognition prototype software }\end{array}$ & 4.54 & 0.82 & Very good \\
\hline \multicolumn{1}{|c|}{ Average } & 4.53 & 0.75 & Very good \\
\hline
\end{tabular}

From Table 9 the satisfaction evaluation results of the language recognition model software found that most users can use the system effectively. The researcher conducted a system satisfaction assessment form. Overall, the assessment was at a high level $(\bar{X}=4.54)$, divided into 4 aspects: the design aspect was at a very good level ( $\bar{X}=$ 4.56) the content aspect was at a very good level ( $\bar{X}=4.55$ ) the usability aspect was in the Good level $(\bar{X}=4.48)$.
Overall aspect of sign language image recognition prototype software is very good ( $\bar{X}=4.54)$ and when average all aspects are at very good level $(\bar{X}=4.53)$.

\section{CONCLUSION}

Development of Thai Sign Language Image Recognition System by using radial inverse force histogram technique used in image characterization process and maximum-minimum boundary value for use in image recognition process. In this research, the experiments were divided into 2 parts: 1) the American Sign Language Image Recognition Experiment and 2) the Thai Sign Language Image Recognition Experiment. The images are divided into 36 different groups, consisting of 26 alphabetic images (AZ) and 10 numbers (0-9). Thai Sign Language image recognition uses immutable images 2 Dimension (2D Invariant images) which divides the image into 61 groups consisting of 44 letters (A-Z), 7 vowels and 10 numbers (0-9). Each group of images will be rotated (Rotation), enlarged (Scaling) and moved the image's position (Translation) in different ways into 6 subgroups. All images are divided into 2 parts: 1) 70\% of image for training and 2) 30\% of image for testing.

The retrieval efficiency measures are divided into 2 parts: 1) American Sign Language Image Recognition and 2) Thai Sign Language Image Recognition. When compared to the Angular histogram method, the mean of image accuracy was 0.86. The recall of the average American Sign Language image was 0.91 . The accuracy value for the average Thai sign language image was 0.78 . The recall of the average Thai sign language images was 0.89 . The Histogram of radial inverse forces combined with measurement of image similarity with maximum-minimum boundary values, the accuracy for average American Sign language image was 0.99 and the recall for American Sign language image averaged 1.00. The mean accuracy for Thai Sign Language images was 0.89 and the recall for Thai Sign Language image averaged 0.96. The results of the visual recognition performance measurement of both American Sign Language and Thai Sign Language images were very good compared to the other methods.

\section{REFERENCES}

1. A. Jesus, P. Anibal, and H. Valeria. "Visual and Phonological Coding in Working Memory and Orthographic Skills of Deaf Children Using Chilean Sign Language", American Annals of the Deaf, vol 152, no.5, 2008, pp. 467-479

2. A. Saiianhar, G. Lu, D. Zhang, and W. Zhou. "A Composite Descriptor for Shape Retrieval" International Conference on Computer and Information Science. IEEE Computer Society. (2007).

3. American Sign Language. (2021, January 12). American Sign Language Fingerspelling [Online]. Available: http://www.lifeprint.com

4. B.S. Manjunath, J.R. Ohm, V. Vasudevan and A. Yamada. "Color and Texture Descriptor" IEEE Transactions on Circuits and Systems for Video Technology. vol.11 no.6, June 2001.

5. D. Zhang and G. Lu. A Comparative Study on Shape Retrieval Using Fourier Descriptors with Different Shape Signatures Proc. of 5th Asian Conference on Computer Vision. (2008).

6. D.P. Huiismans, and N. Sebe. "How to Complete Performance Graphs in Content based Image Retrieval: Add Generality and Normalize Scope." IEEE Transactions on Pattern Analysis and Machine Intelligence. vol.27, no.2, 2005, pp.245-251.

Published By:

Blue Eyes Intelligence Engineering and Sciences Publication

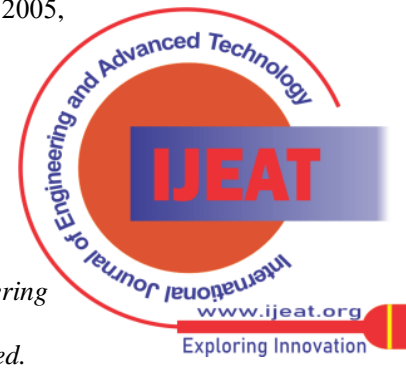


7. E. Cheng, N. Xie, H. Ling and V. Megalooikonomou. "Mammographic Image Classification using Histogram Intersection.” IEEE International Symposium on Biomedical Imaging: From Nano to Macro (ISBI). 7 (2010) pp.197-200.

8. I. Guler. and ED. Ubeyli. "Adaptive neuro-fuzzy inference system for classification of EEG signals using wavelet coefficients." Journal of Neuro Science Methods. 2005, pp.1-9.

9. International Phonetic Alphabet. (2021, January 12). International Phonetic Association [Online]. Available: http://www.langsci.ucl.ac.uk/ipa_chart_(c)2005.pdf

10. J. Niwatphan. Comparative analysis of verbs in Thai Sign Language and Thai Language. Thesis of Master of Arts Kasetsart University.

11. J.M. Geusebroek, G.J. Burghouts and A.W.M. Smeulders. "The Amsterdam library of object images.” International Journal of Computer Vision. 2005, pp.13-122.

12. K. Anil. Fundamentals of Digital Image Processing. Prentice-Hall International Englewood Cliffs. NJ (1989).

13. K. Krairiksh. (2021, January 17). Thai finger spelling [Online] Available: http://pirun.ku.ac.th/ fhumalt/THSL/THSL/THSLindex.html

14. K. Linda, L. Lyle, and S. Lori. "Visual Similarity between Manual and Printed Alphabet Letters", Augmentative and Alternative Communication, vol. 10, no. 2, 1994, pp. 87-95.

15. L. Peter. A Course in Phonetics, 5th ed. Boston: Thomson Wadsworth. 2006.

16. NECTEC's Web Base Learning. (2021, February 6). learn thai sign language [Online]. Available: http://www.nectec.or.th/ courseware/signlanguage/

17. P. Anibal, A. Jesus and H. Valeria. "Fingerspelling and Sign Language as Alternative Codes for Reading and Writing Words for Chilean Deaf Signers", American Annals of the Deaf, vol. 151, no. 3, 2006, pp.299-310.

18. Sun Microsystems. (2021, February 5). Databases and MIDP, Part 1 Understanding the Record Management System [Online]. Available: http://developers.sun.com/mobility/midp/articles/databaserms/

19. Sun Microsystems. (2021, February 5). The Java ME Platform [Online]. Available: http://java.sun.com/javame/

20. Thai Sign Language Book. Association of the Deaf of Thailand Volume 1. Bopit Printing Co., Ltd.

21. Thai. (2021, January 21). Report on the Current Status of United Nations Romanization Systems for Geographical Names, compiled by the UNGEGN Working Group on Romanization Systems [Online] Available: http://www.roin.go.th/th/profile/index.php

22. The Royal Institute. (2021, January 18). Criteria for transcribing Thai characters into transcribed Roman characters [Online]. Available: http://www.roin.go.th/th/profile/index.php

23. Wikipedia the free encyclopedia. (2021, February 18). Sign Language [Online]. Available: http://th.wikipedia.org/wiki/ภาษามือ

\section{AUTHORS PROFILE}

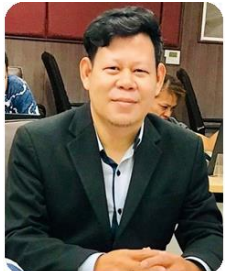

Nattapong Songneam received his Philosophy of Doctor in Information Technology (2002) from Rangsit University, M.Sc. in Computer Science from Rangsit University, and B.Sc. in Computer Science from Rajabhat Songkhla, Thailand. Now he is an Instructor at the Department of Computer Engineering, Faculty of Engineering, Mahidol, Thailand. His interests are in internt of things, artificial intelligence, pattern recognition, image retrieval, speech recognition, fuzzy system, and swarm intelligence.

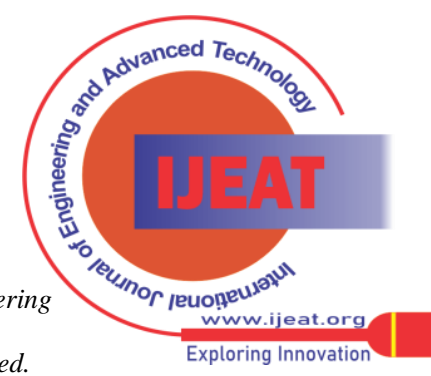

